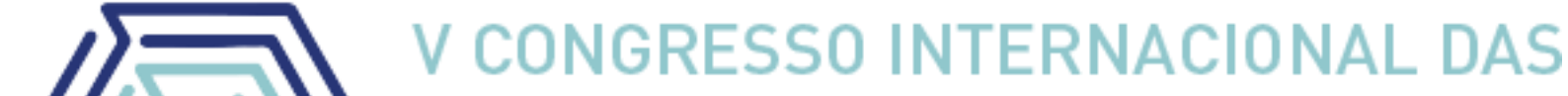 LICENCIATURAS COINTER - PDVL 2018
}

\section{DETERMINAÇÃO DE CÁLCIO EM AMOSTRAS DE SUPLEMENTO ALIMENTAR: UM ESTUDO ESTATÍSTICO COMPARATIVO}

\section{DETERMINATION OF CALCIUM IN SAMPLES OF FOOD SUPPLEMENT: A COMPARATIVE STATISTICAL STUDY}

\author{
Apresentação: Pôster \\ Luiz Brito de Souza Filho ${ }^{1}$; Ézio Raul Alves de Sá2 ; Jorge Roberto Assunção Cardoso ${ }^{3}$ Carlos \\ Eduardo Gonçalves Maia ${ }^{4}$; Tiago Linus Silva Coelho ${ }^{5}$
}

\section{DOI: https://doi.org/10.31692/2358-9728.VCOINTERPDVL.2018.00193}

\section{Introdução}

O envelhecimento populacional é um fenômeno que ocorre em todo mundo. Com o envelhecimento há uma perda gradual de massa óssea que resulta em osteopenia e osteoporose (BEDANI 2005).

A osteoporose, foi identificada como sendo um grave problema de saúde pública. É uma doença que se manifesta na fase tardia da vida, podendo ter origem durante o crescimento do esqueleto. É um problema de saúde verificado em todas as partes do mundo. A partir dos 50 anos, $30 \%$ das mulheres e $13 \%$ dos homens poderão sofrer algum tipo de fratura, estimando-se que a incidência de fraturas irá quadruplicar nos próximos 50 anos, em decorrência do aumento da expectativa de vida (ILICH 2000).

O risco cumulativo de fraturas ao longo da vida para uma mulher de 50 anos com osteoporose é $60 \%$ mais alto em relação aos homens de mesma idade. Para idosos em instituições de cuidados residenciais ou casas de repouso , o risco anual de queda é $>50 \%$. Os locais mais comuns de fratura osteoporótica são o quadril, o úmero, o punho e a coluna. Aproximadamente 5 a $20 \%$ desses pacientes morrem dentro de um ano e $50 \%$ dos sobreviventes apresentam dificuldades em realizar atividades cotidianas e, portanto, precisam de cuidados extras. Muitos idosos que caem apresentam alta incidência de quedas recorrentes

\footnotetext{
${ }^{1}$ Química, Universidade Federal do Piauí e Instituto Federal do Piauí, luiz.brito@ifpi.edu.br

${ }^{2}$ Química, Universidade Federal do Piauí e Instituto Federal do Piauí, ezio.sa@ifpi.edu.br

${ }^{3}$ Química, Instituto Federal do Piauí, iracardoso@ifpi.edu.br

${ }^{4}$ Química, Instituto Federal do Ceará, Eduardo.maia@ifce.edu.br

${ }^{5}$ Doutorando, Universidade Federal do Piauí, tiagolinusquimico@gmail.com
} 
(PINHEIRO 2010). Dois nutrientes, cálcio e vitamina D, são especialmente necessários para se ter ossos fortes. O cálcio é essencial para a manutenção óssea, enquanto o papel da vitamina D é ajudar na absorção do cálcio e na manutenção da densidade óssea (COOK 1991).

O tratamento inicial da osteoporose deve ser realizado através da suplementação de cálcio e vitamina $\mathrm{D}$, utilizando-se diferentes sais de cálcio. $\mathrm{O}$ mais indicado é o carbonato de cálcio, pois apresenta uma maior quantidade de cálcio elementar, da ordem de $40 \%$. O citrato de cálcio apresenta $21 \%$ de cálcio elementar e o lactato de cálcio $13 \%$. Aconselha-se a reposição de 500 mg a 1 g por dia, devendo ser ingerido às refeições, para facilitar a absorção (AUWERX 1986).

Existem diferentes métodos analíticos de determinação de cálcio em amostras, muitas vezes estes, não apresentados de forma adequada, proporcionando um entrave para o pensamento crítico e decisivo do aluno.

Com isso, foi desenvolvido e implementado no IFCE - Campus Ubajara com os alunos da disciplina de Química Analítica Qualitativa um experimento de laboratório em duas semanas, no qual o teor de cálcio dos comprimidos (SOUZA et al 2012) de suplemento comercial é determinado por dois métodos analíticos diferentes (Figura 1).

$\mathrm{Na}$ primeira semana, a análise é realizada por titulação complexométrica com ácido etilenodiaminotetracético - EDTA (SKOOG 2009 e BACCAN 2001).

$\mathrm{Na}$ segunda semana, é seguida pela titulação ácido-base com o hidróxido de sódio padrão com uma resina de troca iônica (DIETZ 1986). Posteriormente, os alunos avaliaram a eficácia dos dois métodos em termos da precisão dos resultados (ou seja, o desvio em relação aos valores do rótulo) e considerações como tempo de análise, facilidade e geração de resíduos.

Por fim, os alunos realizaram uma análise estatística para determinar se os resultados obtidos pelos dois métodos são equivalentes (SAMIDE 2004). Essa sequência foi testada e modificada ao longo de dois semestres e foi realizada com sucesso por 90 alunos até o momento.

Figura 1- resume os procedimentos empregados para a análise dos comprimidos do suplemento alimentar.

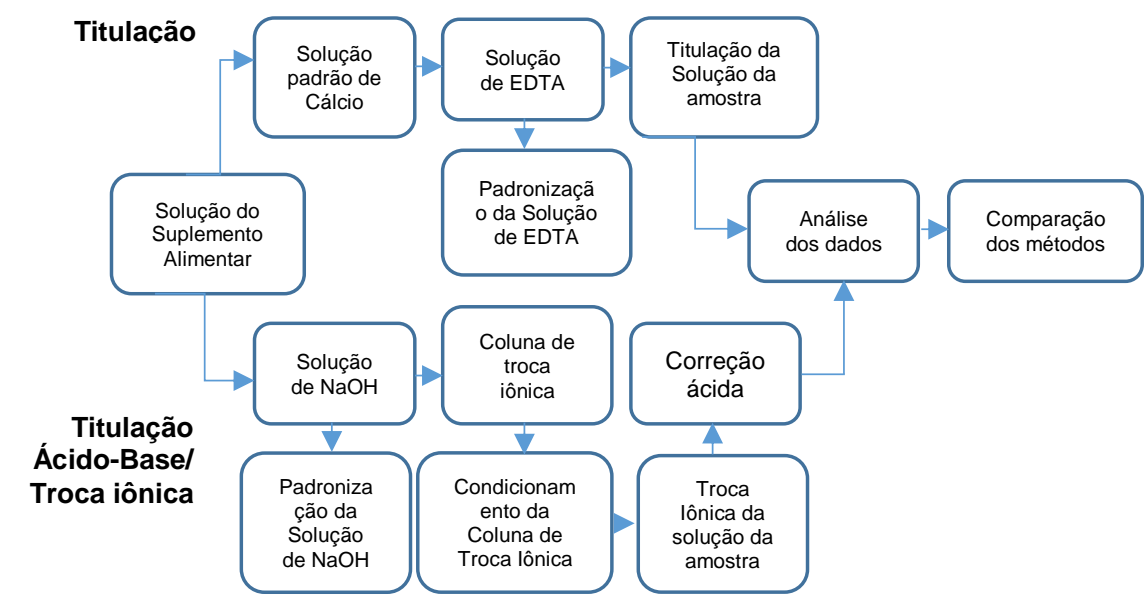




\section{Materiais e Procedimentos}

Os reagentes utilizados, incluindo ácido clorídrico $(\mathrm{HCl})$, carbonato de cálcio $\left(\mathrm{CaCO}_{3}\right)$, ácido etilenodiaminotetracético (como o seu sal dissódico, $\mathrm{Na}_{2}$ EDTA), hidróxido de sódio $(\mathrm{NaOH})$, cloreto de magnésio $\left(\mathrm{MgCl}_{2}\right)$, tampão de amónia ( $\left.\mathrm{pH} 10\right)$, indicador de calmagita e indicador de fenolftaleína, foram grau de reagente analítico. O hidrogeno-ftalato de potássio (KHP) foi o padrão primário. Todas as soluções foram preparadas usando água Milli-Q2 (18 $\mathrm{M} \Omega$ ). Dowex AG 50W-X8 (EiChroM Technologies, Lisle, IL) serviu como a resina de troca catiônica. Foram utilizadas de uma Farmácia revendedora duas marcas de suplementos comerciais de cálcio alimentar, Calcium Citrate ${ }^{\circledR}$ (21st Century) e Super Cálcio D® (CRV Naturalíssima).

$1^{\text {a }}$ Semana (Tempo: Aproximadamente 2 horas): Os alunos utilizaram três comprimidos de suplemento de cálcio (qualquer uma das marcas), em seguida pesaram cada um. Os três comprimidos foram então moídos juntos em um pó fino usando um almofariz e pilão. Uma porção pesada do material moído $0,21 \mathrm{~g}$ foi então transferida para um béquer e adicionados 10 mL de HC1 1 M. O béquer foi coberto com um vidro de relógio e a mistura agitada suavemente até a dissolução estar completa, em 10 minutos. Após a dissolução do comprimido, a solução foi transferida para um balão volumétrico de $500 \mathrm{~mL}$ e diluída até à marca com água deionizada.

$0,21 \mathrm{~g}$ de $\mathrm{CaCO}_{3}$ seco em estufa foi tratada do mesmo modo que o descrito para os comprimidos de suplemento, resultando finalmente em $500 \mathrm{~mL}$ de uma solução padrão de cálcio. Em seguida, os estudantes prepararam uma solução de EDTA compreendendo $\mathrm{Na}_{2}$ EDTA (0,80 g), água (100 mL), $\mathrm{MgCl}_{2}$ 0,1 M (2 mL) e $\mathrm{NaOH}(1,2 \mathrm{~g})$.

Uma vez que os sólidos se tenham dissolvido completamente, a solução foi transferida para um balão volumétrico de $500 \mathrm{ml}$ e diluída até à marca com água deionizada. A solução EDTA foi padronizada pela titulação de alíquotas da solução padrão de cálcio. Especificamente, uma porção de $25,00 \mathrm{~mL}$ da solução de cálcio foi transferida por pipeta para cada um dos quatro frascos Erlenmeyer de $250 \mathrm{~mL}$. A cada um foi adicionado $2 \mathrm{~mL}$ do tampão de amoníaco $\mathrm{pH} 10$ e três gotas de Calmagita como indicador. Cada alíquota foi então titulada com a solução de EDTA até que se observe o aparecimento de uma cor azul persistente. A partir da molaridade conhecida da solução de cálcio e do volume tomado para titulação $(25,00 \mathrm{~mL})$, juntamente com o volume de solução de EDTA necessário para atingir o ponto final (tipicamente cerca de 40$45 \mathrm{~mL}$ ), calcula-se a molaridade da solução de EDTA. 
Por fim, três ou mais alíquotas de $25,00 \mathrm{~mL}$ da solução de comprimido de suplemento de cálcio foram tituladas com a solução de EDTA seguindo os mesmos procedimentos descritos para as titulações de padronização. Do volume de solução de EDTA necessário para atingir o ponto final (15-25 mL, dependendo da concentração de cálcio desconhecida), a sua concentração, o volume da solução de suplemento tomada para titulação e a massa de comprimido utilizada na sua preparação, o teor de cálcio do comprimido de suplemento (mg de $\mathrm{Ca}^{2+} /$ comprimido) é calculado. A porção não utilizada da solução do comprimido suplementar foi guardada para ser utilizada na $2^{\mathrm{a}}$ semana da experiência.

$2^{\text {a }}$ Semana (Tempo: Aproximadamente de 4 horas): Os alunos prepararam uma Solução de $\mathrm{NaOH}$ 0,01 M por diluição de uma alíquota de $100 \mathrm{~mL}$ de uma solução estoque comercial de $\mathrm{NaOH}$ 0,1 M a 1 L com água deionizada. Esta solução foi então padronizada pela titulação de frações $(0,050$ - 0,080 g) de KHP secas em estufa e dissolvidas em água (50 mL) até uma cor rosa fraca usando-se fenolftaleína. Em seguida, uma coluna de troca iônica foi preparada colocando-se uma pequena quantidade de lã de vidro no fundo de uma bureta e adicionando-se uma suspensão de Dowex 50W-X8 (50-100 mesh) (6-7 g) em água. A coluna foi então condicionada com $\mathrm{HCl} 4 \mathrm{M}(10 \mathrm{~mL})$ seguida por três lavagens (50 mL cada) com água deionizada, segundo (DIETZ 1986).

Uma alíquota de 10,00 mL da solução do suplemento dietético restante do trabalho da semana anterior foi então lentamente adicionada à coluna. A amostra foi passada lentamente pela coluna e coletada em um frasco de Erlenmeyer de $250 \mathrm{~mL}$. Uma porção de $20 \mathrm{~mL}$ de água deionizada foi então passada através da coluna e coletada no mesmo frasco. Em seguida, o eluato foi titulado com a solução padrão previamente preparada de $\mathrm{NaOH}(0,01 \mathrm{M})$ usando fenolftaleína como indicador. (Um volume final típico é cerca de $25 \mathrm{~mL}$.) Esse processo foi repetido em triplicata em amostras adicionais. Como o ácido foi adicionado durante a preparação da solução de suplemento dietético, uma correção deve ser aplicada aos volumes do ponto final medido. Três alíquotas $(10 \mathrm{~mL})$ da solução de comprimido de suplemento de cálcio foram, portanto, tituladas com $\mathrm{NaOH} 0,01 \mathrm{M}$ padronizado, novamente usando fenolftaleína como indicador, e o volume de titulante necessário (tipicamente, 21-22 mL) foi subtraído do volume necessário para titular a amostra troca iônica.

\section{Resultados e Discussões}

A Tabela 1 resume os resultados obtidos pelos alunos. A precisão e exatidão do método de titulação de ácido-base/troca iônica foi menos eficiente do que para a titulação complexométrica, um resultado esperado, dado ao maior número de etapas (portanto, a maior 
possibilidade de erro) envolvidas no primeiro método. Apesar disso, os resultados não foram estatisticamente diferentes no nível de confiança de $95 \%$.

Tabela 1 - Resultados obtidos pelos estudantes para determinação de cálcio de duas marcas de suplementos alimentar por titulação complexométrica e por Titulação ácido-base/troca iônica

\begin{tabular}{|c|c|c|c|c|}
\hline \multirow{3}{*}{$\begin{array}{l}\text { Amostras } \\
\text { Média (mg de } \mathrm{Ca}^{2+} / \\
\text { comprimido) }\end{array}$} & \multicolumn{2}{|c|}{$\begin{array}{l}\text { Calcium Citrate }{ }^{\circledR} \\
\text { Rótulo - 630mg de } \\
\mathrm{Ca}^{2+} / \text { comprimido }\end{array}$} & \multicolumn{2}{|c|}{$\begin{array}{c}\text { Super Cálcio D® } \\
\text { Rótulo - 600mg de } \\
\mathrm{Ca}^{2+} / \text { comprimido }\end{array}$} \\
\hline & EDTA & Troca Iônica & EDTA & Troca Iônica \\
\hline & 596 & 559 & 608 & 572 \\
\hline \multirow{5}{*}{$\begin{array}{l}\text { Desvio Padrão } \\
\text { \%RSD } \\
\text { Intervalo de Confiança } \\
\text { Desvio, \% } \\
t_{\text {calculado; }} t_{\text {tabelado }}\end{array}$} & 28 & 87 & 31 & 68 \\
\hline & 9,1 & 28 & 9,7 & 33 \\
\hline & $596 \pm 18$ & $559 \pm 31$ & $608 \pm 18$ & $572 \pm 32$ \\
\hline & $+5,49$ & $+7,21$ & $+4,56$ & $-8,13$ \\
\hline & \multicolumn{2}{|c|}{0,$052 ; 3,087$} & \multicolumn{2}{|c|}{2,$383 ; 4,346$} \\
\hline
\end{tabular}

\section{Conclusões}

Esse experimento evidencia a prática de químicos analíticos na escolha de um método para análise de amostras oferecendo vários benefícios. Primeiro, emprega-se reagentes e equipamentos relativamente baratos. Vale ressaltar que ao utilizar amostras do cotidiano, o nível de interesse pelos alunos aumenta. Por fim, ilustra a aplicação de métodos estatísticos em análise química em um nível de sofisticação maior do que a que caracteriza muitos exercícios estatísticos descritos anteriormente para o laboratório de graduação. Empregar suplementos alimentares contendo citrato de cálcio este experimento (um resultado de seu baixo custo e disponibilidade imediata), não vemos nenhuma razão inerente de que os procedimentos descritos não funcionem igualmente bem para aqueles que contêm o correspondente lactato ou carbonato. Trabalhos anteriores demonstraram que o método de titulação ácido-base/troca iônica fornece resultados satisfatórios para suplementos baseados em lactato de cálcio, valendose ressaltar que os métodos aplicados estão coerentes de acordo com a literatura.

\section{Referências}

AUWERX, J; BOUILlON, R. Mineral and Bone Metabolism in Thyroid Disease: A Review, QJM: An International Journal of Medicine, Volume 60, Issue 2, 1 August 1986, Pages $737-752$

BACCAN, N.; ANDRADE J. C.; GODINHO, O. E. S.; BARONE, J. S.; Química Analítica Quantitativa Elementar, $3^{\mathrm{a}}$ ed., Edgard Blücher: São Paulo, 2001

BEDANI, E.; ROSSI, E. A. O consumo de cálcio e a osteoporose. Semina: Ciências Biológicas e da Saúde, Londrina, v.26, n.1, p.3-14, 2005.

COOK, J. D.; DASSENKO, S. A,; WHITTAKER, P. Calcium supplementation: effect on 
iron absorption. The American Journal of Clinical Nutrition , v.53, p.106-111, 1991.

DIETZ, M. L.; The determination of calcium in dietary supplement tablets by ion exchange: A freshman laboratory experiment. Journal of Chemical Education. 1986, 63, 177.

ILICH, J. Z.; KERSTETTER, J. E. Nutrition in bone health revisited: a story beyond calcium. Journal of the American College of Nutrition, New York, v.19, p.715-737, 2000

PINHEIRO, M. M.; EIS, S.R. Epidemiologia de fraturas pela osteoporose no Brasil: o que temos e o que precisamos. Arq Bras Endocrinol Metab 2010; 54 (2): 164-70

SAMIDE, M. J. Statistical comparison of data in the analytical laboratory. Journal of Chemical Education. 2004, 81, 1641-1643.

SKOOG, D. A.; HOLLER, F. J.; CROUCH, S. R. Princípios de Análise Instrumental. $6^{\text {a }}$ ed. Porto alegre: Editora Bookman, 2009.

SOUZA, S. P. M. C.; MORAIS, F. E.; SANTOS, E. V.; SILVA, M. L.; MARTINEZ-HUITLE, C. A.; FERNANDEZ, N. S. Determinação do teor de cálcio em comprimido à base de lactato de cálcio utilizado no tratamento da osteoporose. Química Nova, Vol. 35, No. 7, 1355-1359, 2012. 